\title{
KAJIAN RANTAI PASOK DAN NILAI TAMBAH KOMODITI CABAI RAWIT DI KABUPATEN KUPANG PROVINSI NUSA TENGGARA TIMUR
}

\author{
Gregorius Gehi Batafor ${ }^{1}$, Yason Edison Benu ${ }^{1}$ \\ ${ }^{1}$ Politeknik Pertanian Negeri Kupang
}

\begin{abstract}
Abstrak
Penelitian ini bertujuan menganalisa rantai nilai dan mengkaji nilai tambah komoditi cabai rawit. Metodologi penelitian kualitatif dan kuantitatif, sedangkan teknik analisis data menggunakan metode hayami dan analisis biaya pokok. Hasil analisis rantai nilai menunjukkan bahwa tingkat keuntungan pada pedagang pengumpul sebesar Rp. 5.306 per kg, dan pada pedagang pengecer mencapai Rp. 10.806 per kg, sedangkan keuntungan petani Rp. 1.806 per kg. RC rasio yang dihasilkan yaitu 1,14 pada tingkat petani, 1,31 pada tingkat pedagang pengumpul dan 1,45 pada tingkat pedagang pengecer. Hasil analisis biaya pokok, penyimpanan dingin selama 3 bulan membutuhkan biaya sebesar Rp. 708,146 per kg. Nilai tersebut lebih rendah dibandingkan dengan penyimpanan konvensional sebesar Rp. 1.372 per kg. Berdasarkan wawancara mengenai prediksi harga 3 bulan ke depan dan nilai susut terdapat perbedaan signifikan antara penyimpanan konvensional dengan penyimpanan dingin. Keuntungan penyimpanan dingin lebih besar dari pada penyimpanan konvensional, yaitu $\mathrm{Rp} .13 .417$ per $\mathrm{kg}$ selama penyimpanan 3 bulan sedangkan penyimpanan konvensional Rp. 3000 per $\mathrm{kg}$. Peningkatan tersebut diperoleh dengan asumsi harga sebelum disimpan Rp. 22.250 per kg, dan harga jual setelah disimpan Rp. 35.000 per kg.
\end{abstract}

Kata Kunci: Rantai Nilai, Teknologi Penyimpanan Dingin

\section{Abstract}

This study aims to analyze the value chain and assess the added value Soe tangerine products. The results of the value chain analysis show that the level of profit for the trader is IDR 5,306 per $\mathrm{kg}$, and retailers reach IDR 10,806 per $\mathrm{kg}$, while the farmers' profit is IDR 1,806 per $\mathrm{kg}$. The resulting $R C$ ratio is 1.14 at the farmer level, 1.31 at the collector trader level and 1.45 at the retailer trader level. The results of the analysis of basic costs, cold storage for 3 months requires a fee of IDR 708,146 per $\mathrm{kg}$. This value is lower compared to conventional storage of IDR 1,372 per $\mathrm{kg}$. Based on interviews regarding price predictions for the next 3 months and shrinkage values there is a significant difference between conventional storage and cold storage. The advantage of cold storage is greater than conventional storage, which is IDR 13,417 per $\mathrm{kg}$ for 3 months storage while conventional storage is IDR 3,000 per kg. The increase was obtained assuming the price before being saved IDR 22,250 per $\mathrm{kg}$, and the sale price after saving is IDR 35,000 per $\mathrm{kg}$.

Keywords: Value Chain, Cold Storage Technology

\section{Pendahuluan}

Cabai rawit merupakan salah satu icon Kabupaten kupang, saat ini memiliki banyak persoalan. Pada sentra produksi, petani selalu berada pada posisi yang lemah dikarenakan harga yang rendah bila ingin cepat terjual atau akan mengalami susut bila ingin disimpan. Tingginya harga cabai rawit pada tingkat pengecer di pasar, ternyata tidak terdistribusi dengan baik ke tingkat petani sehingga petani sebagai produsen hanya memperoleh porsi pendapatan terkecil dan selalu fluktuatif.

Dari sisi konsumen, cabai rawit hanya dibutuhkan dalam jumlah sedikit tetapi selalu kontinu. Apabila tidak dilakukan distribusi penawaran dengan baik, dapat mengakibatkan kelangkaan suplai di pasaran ketika tidak pada masa panen, apalagi mengingat tingginya angka 
penyusutan dan kerusakan (karakteristik komoditas pertanian yang pada umumnya perishable dan fragile). Pada kondisi ini, pedagang pengepul maupun pengecer akan mendatangkan cabai rawit dari daerah luar seperti Malang dan Bali untuk dapat memenuhi permintaan masyarakat. Persoalan ini mungkin dapat dicarikan alternatif pemecahannya, mengingat jumlah produksi cabai rawit sebenarnya lebih besar daripada jumlah konsumsi masyarakat terhadap komoditi cabai rawit di wilayah NTT.

Persoalan penyusutan dan tingkat kerusakan hasil panen petani cabai rawit dapat diminimalisir dengan adanya proses penanganan pasca panen berupa penyimpanan yang baik sehingga mampu menyelamatkan surplus produksi cabai rawit dan dapat mencegah rendahnya harga jual di pasaran yang tentunya sangat merugikan para petani cabai rawit itu sendiri.

Teknologi penyimpanan menjadi hal krusial dalam mengendalikan pasokan cabai rawit dan berpotensi untuk meningkatkan nilai tambah. Penyimpanan yang baik dapat memperpanjang umur simpan sehingga dapat mengurangi tingkat penyusutan dan kerusakan pada saat panen raya dan menggunakannya pada saat kekurangan. Analisis rantai nilai diperlukan untuk mengetahui stakeholder mana yang perlu melakukan perbaikan input teknologi untuk meningkatkan nilai tambah (Kotler, P. \& Armstrong, 2008). Pendekatan rantai nilai membantu memahami bagaimana kondisi membentuk rantai nilai, melakukan identifikasi siapa yang menanganinya, menjawab pertanyaan yang luas dan spesifik, serta melakukan pendekatan membangun hubungan kemitraan (Bahtiar J, 2011).

\section{Metode Penelitian}

Penelitian dilakukan di Kabupaten kupang Provinsi Nusa Tenggara Timur pada bulan Maret sampai bulan Oktober tahun 2019. Pemilihan lokasi dilakukan secara sengaja (purposive), dengan pertimbangan bahwa kabupaten tersebut merupakan sentra produksi cabai rawit di Provinsi Nusa Tenggara Timur. Penelitian rantai distribusi dilakukan mulai dari petani, pedagang pengumpul dan pedagang pengecer dan konsumen akhir pada beberapa pasar induk di Kota Kupang.

Data primer bersumber dari petani cabai rawit mengenai luas tanam, biaya produksi, jumlah produksi, jumlah susut di setiap tindakan pascapanen dan harga jual. Data primer yang diperoleh dari pedagang pengumpul dan pedagang pengecer berupa biaya pembelian, biaya transportasi, susut transportasi, susut persediaan barang dagangan, biaya tenaga kerja, biaya storage, biaya sewa lapak dan biaya overhead lainnya. Data sekunder diperoleh dari laporan instansi pemerintah dan berbagai literatur pendukung lainnya.

Fokus penelitian dibagi menjadi tiga aktivitas yaitu (1) memetakan seluruh persoalan dan menganalisis rantai nilai dalam setiap rantai distribusi; (2) menentukan stakeholders yang tepat dalam penerapan teknologi penyimpanan pada rantai distribusi; dan (3) mengkaji nilai tambah akibat penerapan teknologi penyimpanan cabai rawit.

Analisis nilai tambah menggunakan metode Hayami. Data-data yang diperlukan untuk menghitung nilai tambah berupa jumlah output, bahan baku dan tenaga kerja per periode, data harga output, upah rata-rata, harga bahan baku dan biaya sumbangan input lainnya.

Langkah-langkah dalam analisis nilai tambah menurut Hayami, (1987)adalah:

1. Membuat arus komoditas yang menunjukkan bentuk-bentuk komoditas, lokasi, lama penyimpanan dan perlakuan yang pernah diberikan kepada komoditas bersangkutan.

2. Mengidentifikasikan setiap transaksi yang terjadi menurut perhitungan finansial.

3. Memilih dasar perhitungan. 
4.

Beberapa variabel yang terkait dalam analisis nilai tambah yaitu:

1. Faktor konversi menunjukkan banyaknya output yang dihasilkan dari satu satuan input.

2. Koefisien tenaga kerja langsung, menunjukkan tenaga kerja langsung yang diperlukan untuk mengolah satu satuan input.

3. Nilai output, menunjukkan nilai ouput yang dihasilkan dari satu satuan input.

Analisis nilai tambah pada subsistem pengolahan, menghasilkan informasi luaran sebagai berikut:

1. Nilai tambah (Rp),

2. Rasio nilai tambah (\%), menunjukkan persentase nilai tambah dari produk,

3. Balas jasa tenaga kerja (Rp), menunjukkan upah yang diterima oleh tenaga kerja langsung untuk memperoleh satu-satuan bahan baku,

4. Bagian tenaga kerja (\%), menunjukkan persentase imbalan tenaga kerja dari nilai tambah,

5. Keuntungan (Rp), menunjukkan bagian yang diterima oleh pemilik faktor produksi karena menanggung risiko usaha,

6. Tingkat keuntungan (\%), menunjukkan persentase keuntungan terhadap nilai tambah,

7. Marjin menunjukkan besarnya kontribusi pemilik faktor produksi selain bahan baku yang digunakan dalam proses produksi.

Tabel 1. Analisis Nilai Tambah Metode Hayami

\begin{tabular}{|c|c|c|}
\hline \multicolumn{3}{|c|}{ Output, Input dan Harga } \\
\hline 1 & Output (Kg/Periode) & A \\
\hline 2 & Bahan Baku (Kg/Periode) & $\mathrm{B}$ \\
\hline 3 & Tenaga Kerja (HOK/periode) & $\mathrm{C}$ \\
\hline 4 & Faktor Konversi (Kg Output/Kg Bahan Baku) & $\mathrm{D}=\mathrm{A} / \mathrm{B}$ \\
\hline 5 & Koefisien Tenaga Kerja (HOK/Kg Bahan Baku) & $\mathrm{E}=\mathrm{C} / \mathrm{B}$ \\
\hline 6 & Harga Output $(\mathrm{Rp} / \mathrm{Kg})$ & $\mathrm{F}$ \\
\hline 7 & Upah Rata-rata Tenaga Kerja ( Rp/HOK) & $\mathrm{G}$ \\
\hline \multicolumn{3}{|c|}{ Pendapatan dan Keuntungan } \\
\hline 8 & Harga Bahan Baku (Rp/Kg) & $\mathrm{H}$ \\
\hline 9 & Sumbangan Input Lain $((\mathrm{Rp} / \mathrm{Kg})$ & I \\
\hline 10 & Nilai Output $(\mathrm{Rp} / \mathrm{Kg})$ & $\mathrm{J}=\mathrm{D} \times \mathrm{F}$ \\
\hline 11.a. & Nilai Tambah $(\mathrm{Rp} / \mathrm{Kg})$ & $\mathrm{K}=\mathrm{J}-\mathrm{I}-\mathrm{H}$ \\
\hline b. & Rasio Nilai Tambah (\%) & $\mathrm{L}=(\mathrm{K} / \mathrm{J}) \times 100 \%$ \\
\hline 12.a. & Imbalan Tenaga Kerja (Rp/Kg) & $\mathrm{M}=\mathrm{Ex} G$ \\
\hline b. & Bagian Tenaga Kerja $(\%)$ & $\mathrm{N} \%=(\mathrm{M} / \mathrm{K}) \times 100 \%$ \\
\hline 13.a. & Keuntungan $(\mathrm{Rp} / \mathrm{Kg})$ & $\mathrm{O}=\mathrm{K}-\mathrm{M}$ \\
\hline b. & Tingkat Keuntungan $(\%)$ & $\mathrm{P} \%=(\mathrm{O} / \mathrm{J}) \times 100 \%$ \\
\hline \multicolumn{3}{|c|}{ Balas Jasa dari Masing-masing Faktor Produksi } \\
\hline 14.a. & Marjin $(\mathrm{Rp} / \mathrm{Kg})$ & $\mathrm{Q}=(\mathrm{J}-\mathrm{H})$ \\
\hline b. & Imbalan Tenaga Kerja (\%) & $\mathrm{R} \%=(\mathrm{M} / \mathrm{Q}) \times 100 \%$ \\
\hline c. & Sumbangan Input Lain $(\%)$ & $\mathrm{S} \%=(\mathrm{I} / \mathrm{Q}) \times 100 \%$ \\
\hline d. & Keuntungan $(\%)$ & $\mathrm{T} \%=(\mathrm{O} / \mathrm{Q}) \times 100 \%$ \\
\hline 15 & $\mathrm{RC}$ rasio & $\mathrm{U}=\mathrm{J} /(\mathrm{H}+\mathrm{I}+\mathrm{M})$ \\
\hline
\end{tabular}

Sumber: Hayami (1987) 


\section{Hasil Dan Pembahasan}

\section{Rantai Nilai}

Rantai distribusi cabai rawit seperti pada gambar di bawah ini, antara lain stakeholders cabai rawit terdiri dari petani, pedagang pengumpul, pedagang pengecer dan konsumen akhir.

Gambar 1. Rantai Distribusi Cabai Rawit

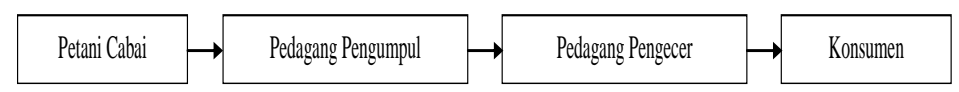

Sumber : Hasil Penelitian

Analisis rantai nilai pascapanen telah dilakukan dengan menggunakan metode Hayami yang menunjukkan marjin, nilai tambah dan keuntungan setiap stakeholder dalam rantai distribusi cabai rawit dari petani, pedagang pengumpul dan pedagang pengecer, seperti pada tabel berikut :

Tabel 2. Analisis Nilai Tambah Cabai Rawit

\begin{tabular}{|c|c|c|c|c|}
\hline \multirow[t]{2}{*}{ No } & \multirow[t]{2}{*}{ Uraian } & \multicolumn{3}{|c|}{ Cabai Rawit } \\
\hline & & Petani & Pengumpul & Pengecer \\
\hline \multicolumn{5}{|c|}{ Output, Input dan Bahan Baku } \\
\hline 1 & Output (Kg/Periode) & 50000 & 50000 & 50000 \\
\hline 2 & Bahan Baku (Kg/Periode) & 50000 & 50000 & 50000 \\
\hline 3 & Tenaga Kerja (HOK/periode) & 69.120 & 23.040 & 23.040 \\
\hline 4 & Faktor Konversi (Kg Output/Kg Bahan Baku) & 1 & 1 & 1 \\
\hline 5 & Koefisien Tenaga Kerja (HOK/Kg Bahan Baku) & 1,38 & 0,46 & 0,46 \\
\hline 6 & Harga Output $(\mathrm{Rp} / \mathrm{Kg})$ & 15000 & 22250 & 35000 \\
\hline 7 & Upah Rata-rata Tenaga Kerja ( Rp/HOK) & 321,18 & 963,54 & 963,54 \\
\hline \multicolumn{5}{|c|}{ Pendapatan dan Keuntungan } \\
\hline 8 & Harga Bahan Baku (Rp/Kg) & 12750 & 16500 & 23750 \\
\hline 9 & Sumbangan Input Lain $((\mathrm{Rp} / \mathrm{Kg})$ & 0 & 0 & 0 \\
\hline 10 & Nilai Output (Rp/Kg) & 15000 & 22250 & 35000 \\
\hline $11 \mathrm{a}$ & Nilai Tambah $(\mathrm{Rp} / \mathrm{Kg})$ & 2250 & 5750 & 11250 \\
\hline $\mathrm{b}$ & Rasio Nilai Tambah (\%) & 0,150 & 0,258 & 0,321 \\
\hline $12 \mathrm{a}$ & Imbalan Tenaga Kerja (Rp/Kg) & 444 & 444 & 444 \\
\hline $\mathrm{b}$ & Bagian Tenaga Kerja (\%) & 0,20 & 0,08 & 0,04 \\
\hline $13 a$ & Keuntungan (Rp/Kg) & 1806 & 5306 & 10806 \\
\hline $\mathrm{b}$ & Tingkat Keuntungan (\%) & 0,12 & 0,24 & 0,31 \\
\hline \multicolumn{5}{|c|}{ Balas Jasa dari Masing-masing Faktor Produksi } \\
\hline $14 \mathrm{a}$ & Marjin $(\mathrm{Rp} / \mathrm{Kg})$ & 2250 & 5750 & 11250 \\
\hline $\mathrm{b}$ & Imbalan Tenaga Kerja (\%) & 0 & 0 & 0 \\
\hline $\mathrm{c}$ & Sumbangan Input Lain (\%) & 0 & 0 & 0 \\
\hline $\mathrm{d}$ & Keuntungan $(\%)$ & 0,80 & 0,92 & 0,96 \\
\hline 15 & $\mathrm{RC}$ rasio & 1,14 & 1,31 & 1,45 \\
\hline
\end{tabular}

Sumber: Hasil Penelitian

Hasil analisis rantai nilai menunjukkan bahwa tingkat keuntungan pada pedagang pengumpul sebesar 5.306 rupiah per $\mathrm{kg}$, dan pada pedagang pengecer mencapai 10.806 rupiah per kg, sedangkan bila dibandingkan dengan keuntungan petani sebagai produsen hanya sebesar 1.806 rupiah per kg. Apabila dihitung selisih keuntungan antara setiap pelaku dalam rantai distribusi komoditi cabai rawit, maka petani yang merupakan produsen dan sebagai hulu alir produk tersebut hanya menerima nilai tambah sebesar 2.250 rupiah per $\mathrm{kg}$, sedangkan pedagang pengumpul menerima nilai tambah sebesar 5.750 rupiah per $\mathrm{kg}$ dan 
pedagang pengecer menerima nilai tambah sebesar 11.250 rupiah per $\mathrm{kg}$. $\mathrm{RC}$ rasio yang dihasilkan yaitu 1,14 pada tingkat petani, 1,31 pada tingkat pedagang pengumpul dan 1,45 pada tingkat pedagang pengecer.

Pedagang pengumpul mendistribusikan cabai rawit kepada pedagang pengecer dengan komponen biaya yang dikeluarkan berupa biaya sewa lapak untuk penampungan dan biaya tenaga kerja untuk proses jual beli ke pedagang pengecer. Selama penjualan cabai rawit di pasar rakyat terdapat susut renstan yang merupakan susut yang terjadi karena penyimpanan di pasar selama cabai rawit tersebut belum dibeli oleh pedagang pengecer. Kondisi pasar yang tidak terkendali RH dan suhu dapat menyebabkan susut bobot tersebut. Menurut Rustini S, (2011) Kenaikan susut bobot dapat disebabkan kelembaban (RH) lingkungan dan suhu serta lama penyimpanan. Berdasarkan biaya, harga dan susut yang terjadi di pasar rakyat dan dihitung menggunakan Hayami, pedagang pengumpul mendapatkan keuntungan sebesar 5.306 rupiah per $\mathrm{kg}$, dan pada pedagang pengecer mencapai 10.806 rupiah per $\mathrm{kg}$, sedangkan bila dibandingkan dengan keuntungan petani sebagai produsen hanya sebesar 1.806 rupiah per $\mathrm{kg}$.

Hasil analisis rantai nilai pascapanen komoditi cabai rawit, bahwa keuntungan pascapanen petani jauh lebih rendah daripada pedagang pengumpul dan pedagang pengecer di pasar rakyat. Hal ini dapat disebabkan oleh rendahnya harga yang diterima petani, hanya sebesar 15.000 rupiah per kg karena sedang pada musim panen raya. Nilai RC rasionya pun lebih rendah dibandingkan dengan pelaku lainnya, petani memiliki $\mathrm{RC} 1,14$, pedagang pengumpul memiliki RC hingga 1,31 dan pedagang pengecer memiliki RC mencapai 1,45. Nilai RC lebih dari satu menujukkan bahwa petani, pedagang pengumpul dan pedagang pengecer di pasar rakyat tidak mengalami kerugian. Namun demikian, salah satu ukuran perdagangan yang adil dapat ditunjukkan degan RC yang hampir sama sepanjang rantai distribusi produk tersebut. Menurut Dirjen P2HP (Direktorat Jenderal Pengolahan dan Pemasaran Hasil Pertanian, 2006) tata niaga produk-produk pertanian umumnya masih dikuasai oleh tengkulak/pedagang perantara antara lain pedagang pengumpul maupun pedagang pengecer sehingga marjin petani relatif lebih kecil dibandingkan dengan para pelaku lainnya. Hal senada disampaikan oleh Mayrowani et al (2013) menemukan bahwa yang menerima marjin keuntungan terbesar dalam pemasaran produk-produk pertanian dari pusat produksi ke pusat konsumsi adalah pedagang perantara baik pedagang pengumpul, pedagang pengirim maupun pedangan pengecer di pasar akhir. Triyono et al , (2010)), petani selalu mendapatkan keuntungan kecil dibandingkan pelaku lainnya, ditunjukkan dengan farmer share petani yang lebih rendah. Pada saat tidak pada masa panen raya, tingginya harga produk-produk pertanian di tingkat pengecer dan pasar akhir tidak terdistribusi dengan baik ke tingkat petani sehingga petani mendapatkan bagian kecil dan fluktuatif.

\section{Analisis Biaya Pokok Penyimpanan Dingin}

Penerapan teknologi penyimpanan dingin dapat meningkatkan nilai tambah petani karena melakukan penundaan penjualan sampai harga kembali naik dengan susut yang rendah selama penundaan tersebut. Pengaturan pasokan oleh petani ke pasar menjadi penting untuk mengendalikan harga sehingga petani terhindar dari harga rendah dan memperoleh peningkatan keuntungan terutama di masa panen raya. Mutia et all (2017) menyatakan bahwa penyimpanan dingin temperatur hanya mengalami susut berat 3,5-12\% selama penyimpanan 2 bulan. Prinsip dari perlakuan penyimpanan dingin adalah mengendalikan laju transpirasi, mengendalikan respirasi, mengendalikan/mencegah serangan penyakit, mencegah perubahan-perubahan yang tidak dikehendaki konsumen. Selama penyimpanan 2 bulan tersebut dapat terjadi peningkatan harga produk sehingga keuntungan petani 
bertambah. Namun demikian, perlu ada analisis kelayakan operasional melalui biaya pokok karena investasi penyimpanan dingin sangat tinggi.

Penyimpanan dingin yang menjadi objek kajian merupakan bantuan pemerintah yang dikelola oleh Koperasi Lais Manekat. Spesifikasi umum terdiri dari kapasitas 400 ton dengan dimensi luas 30x25 meter dan mampu mempertahankan suhu 5-10 $\mathrm{C}$. Gambar berikut menampilkan tampak luar gudang penyimpanan cabai rawit keprok Soe yang di dalamnya terdapat coldstorage.

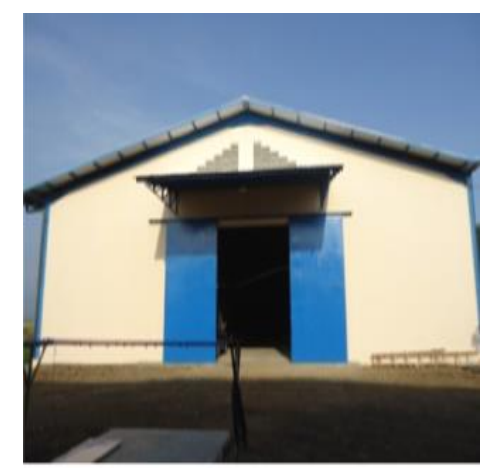

Gambar 2. Bangunan Luar Gudang Penyimpanan Cabai Rawit Berpendingin

Gudang tersebut dilengkapi oleh tiga ruangan. Ruangan pertama digunakan untuk proses pembersihan dan sortasi buah. Ruangan kedua disebut dengan anteroom untuk ruangan precooling sebelum cabai rawit dimasukan ke dalam coldroom (suhu $10-15^{\circ} \mathrm{C}$ ). Ruangan ketiga coldroom untuk penyimpanan dingin cabai rawit (suhu $0-5{ }^{\circ} \mathrm{C}$ ). Gambar berikut menampilkan tataletak gudang penyimpanan cabai rawit berpendingin.

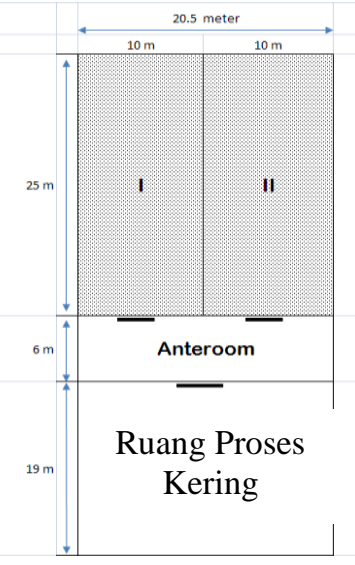

\section{Gambar 3. Tataletak Ruang Pendingin}

Coldstorage dibagi menjadi 3 komponen utama yaitu mesin pendingin, bahan isolasi ruangan dan generator. Gambar 4, 5 dan 6 menampilkan ketiga komponen tersebut. Berikut spesifikasi detail ketiga komponen coldstorage.

Mesin Pendingin $\left(+5^{\circ} \mathrm{C}\right)$

Spesifikasi yang ada adalah sebagai berikut :

- Compressor : unit open 4G.2 HP - Merk Bitzer

- Condensor : unit Air Cooled Condenser Greenhalgh

- Evaporator : unit Air Cooled Evaporator Muller 
- Aksesoris : Check valve, Oil separator, Receiver tank, Filter Drier, Sight Glass, Liquid Solenoid, Valve, Stop kran, Expansion Valve, HLP, chasis, Suctionmeter, ressmeter dan electromotor.

- Panel listrik box : MCB, Overload \& phase digital thermostat

- Refrigerant : R 22

- Power : $380 \mathrm{~V} / 3$ phase / $50 \mathrm{~Hz}$

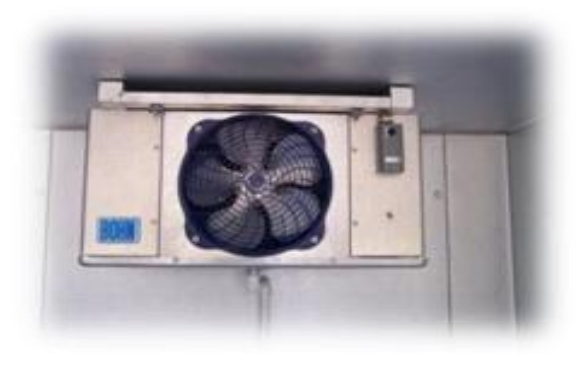

Gambar 4. Komponen Mesin Pendingin

Spesifikasi Komponen Isolasi Ruangan :

- Isolasi Dinding/ Atap

Density : $45 \mathrm{Kg} / \mathrm{m}^{3} \pm 5 \%$

Isolasi $\quad: 0.4 \mathrm{~mm}$ PPGI mengapit $75 \mathrm{~mm}$ polyurethane foa

Join system : semi CamLock

- Isolasi Lantai

Konstruksi lapisan lantai (dari atas ke bawah)

$75 \mathrm{~mm}$ cor beton bertulang

Aluminium foil 2 sisi sebagai Vapor Barrier dan perekat foil tape

$75 \mathrm{~mm}$ polyurethane foam, density $45 \mathrm{Kg} / \mathrm{m}^{3} \pm 5 \%$

Lapisan water proofing

\section{Generator (Genset)}

Gambar 5. Komponen Material Ruangan

Genset diperlukan sebagai cadangan sumber listrik ketika aliran listrik dari PLN terputus. Spesifikasi genset sebagai berikut :

- Kapasitas : $250 \mathrm{kVA}$

- Model : Open Type / $1500 \mathrm{rpm}$

- Voltage : $230 \mathrm{~V} / 380$ Volt, 3 Phase 4 Wire, $50 \mathrm{~Hz}, \mathrm{I}$

- Power Factor: 0.8

- Starter : Electrical Starting

- Pendinginan: Radiator Cooled 
- Perlengkapan: Generator control panel, exhaust flexible pipe, exhaust silencer, battery set, daily tank, safety devicelautomatic shut down.

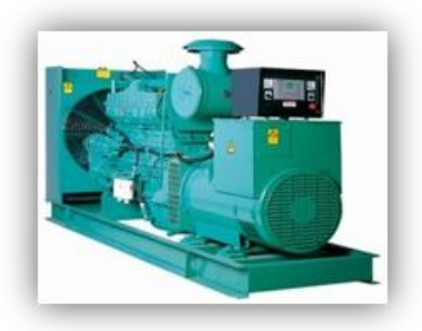

Gambar 6. Komponen Genset

Berdasarkan hasil wawancara mendalam dengan pengurus koperasi diperoleh data biaya tetap dan harga perolehan pendirian coldstorage.

Tabel 3. Biaya Tetap Penyimpanan Dingin

\begin{tabular}{lrcrr}
\hline \multicolumn{1}{c}{ Keterangan } & \multicolumn{1}{c}{ Nilai } & $\begin{array}{c}\text { Biaya } \\
\text { Unvestasi Ekonomis } \\
\text { (Tahun) }\end{array}$ & $\begin{array}{c}\text { Penyusutan } \\
\text { Tahunan }\end{array}$ & $\begin{array}{c}\text { Biaya } \\
\text { Bunga/Tahun } \\
(10 \%)\end{array}$ \\
\hline 1. Bangunan & 1.232 .000 .000 & 20 & 61.600 .000 & 64.680 .000 \\
2. Cold Storage & 2.975 .329 .800 & 20 & 148.766 .490 & 156.204 .815 \\
3. Genset & 250.000 .000 & 5 & 50.000 .000 & 15.000 .000 \\
4. Kabel Listrik & 3.750 .000 & 5 & 750.000 & 225.000 \\
5. Lampu & 7.500 .000 & 5 & 1.500 .000 & 450.000 \\
6. Stop kontak & 4.500 .000 & 5 & 900.000 & 270.000 \\
7. Gudang Peralatan & 292.000 .000 & 20 & 14.600 .000 & 15.330 .000 \\
8. Rak Penyimpanan & 1.800 .000 .000 & 20 & 90.000 .000 & 94.500 .000 \\
9. Kipas & 20.000 .000 & 5 & 4.000 .000 & 1.200 .000 \\
10. Fork Klip & 400.000 .000 & 20 & 20.000 .000 & 21.000 .000 \\
\hline Sumber : Hath
\end{tabular}

Sumber : Hasil Penelitian

Berdasarkan tabel tersebut di atas, biaya terbesar adalah biaya pendirian bangunan sebesar Rp. 1.232.000.000 dan coldstorage sebesar Rp. 2.975.329.800. total kedua biaya investasi tersebut mencapai Rp. 4.207.329.800. Walaupun sumber listrik utama dari PLN, namun fasilitas coldstorage dilengkapi oleh genset untuk antisipasi ketiadaan sumber listrik dari PLN sehingga suhu coldstorage dapat dijaga. Menurut Aung MM, (2014) pengendalian dan manajemen temperatur yang baik merupakan hal yang krusial untuk produk perishabel dan menjamin aman untuk dikonsumsi.

Biaya tetap yang dihitung adalah biaya penyusutan dan biaya bunga modal. Pada tabel di atas menunjukkan bahwa biaya penyusutan paling besar yaitu coldstorage dan pendirian bangunan. Pendirian bangunan diperlukan untuk melindungi coldstorage dari cuaca agar umur ekonomisnya dapat maksimal. Nilai penyusutan dihitung menggunakan metode garis lurus. Perhitungan penyusutan dengan metode garis lurus telah dilakukan oleh Islam, Kabir, \& Kabir, (2008) untuk menghitung depresiasi coldstorage milik pribadi dan milik pemerintah. Dengan metode garis lurus tersebut, persentase penyusutan bergantung umur ekonomis, bila umur ekonomisnya 20 tahun maka persentase penyusutannya seperduapuluh atau $5 \%$ per tahun. Investasi bangunan, coldstorage, gudang peralatan, rak penyimpanan dan forklip memiliki umur ekonomis 20 tahun sehingga nilai penyusutannya $5 \%$ per tahun. Hal ini pun dinyatakan oleh Kart MCO, (2014) bahwa penyusutan bangunan dan coldstorage antara 2 sampai dengan 6\%. Sedangkan untuk bahan-bahan plastik seperti peralatan kabel, lampu dan kipas memiliki umur ekonomis selama 5 tahun sehingga nilai 
penyusutan $20 \%$ per tahun. Kart MCO, (2014) pun menyatakan bahwa nilai penyusutan untuk peralatan pembantu dan berbahan plastik berkisar antara 14 sampai dengan $20 \%$ per tahun.

Nilai bunga $10 \%$ per tahun sebagai acuan untuk menentukan biaya bunga modal. Islam et al., (2008) menggunakan bunga modal sebesar 10\% dari harga pembelian coldstorage. Kart MCO, (2014) menyatakan bahwa bunga modal dan pajak hanya mencapai $4 \%$ setiap tahunnya.

Komponen biaya tidak tetap terdiri dari tenaga kerja, bahan bakar, pemelliharaan dan biaya listrik. Biaya tidak tetap yang dikeluarkan bergantung dari lama operasional coldstorage yang dihitung dalam satuan waktu bulanan karena biaya sewa yang dikenakan kepada petani dalam satuan bulanan. Tenaga kerja coldstorage terdiri dari tenaga kerja tetap sebanyak 4 orang dengan upah Rp. 1.500 .000 setiap orangnya per bulan, sedangkan tenaga kerja borongan maksimal sebanyak 10 orang dengan biaya Rp. 650.000 per orang setiap bulan. Solar Genset hanya digunakan bila mengalami gangguan listrik, terlihat bahwa biaya operasional terbesar adalah biaya listrik (Tabel 4). Menurut Kart MCO, (2014) biaya tidak tetap terbesar coldstorage adalah listrik, bahan bakar dan oli.

Tabel 4. Biaya-biaya Tidak Tetap Penyimpanan Dingin

\begin{tabular}{lr}
\hline \multicolumn{1}{c}{ Keterangan } & $\begin{array}{c}\text { Biaya } \\
\text { Per Bulan }\end{array}$ \\
\hline Tenaga Tetap & 6.000 .000 \\
Tenaga Borongan & 6.500 .000 \\
Solar Genset dan Pemeliharaan & 2.300 .000 \\
Solar Forklip dan Pemeliharaan & 1.800 .000 \\
Biaya listrik & 13.000 .000 \\
Biaya Tidak Tetap (Rp/bulan) & $\mathbf{2 9 . 6 0 0 . 0 0 0}$ \\
\hline
\end{tabular}

Sumber : Hasil Penelitian

Biaya total (B) coldstorage merupakan biaya keseluruhan yang diperlukan untuk mengoperasikan coldstorage, asumsi operasional coldstorage selama 1`kali masa simpan dalam setahun adalah 3 bulan. Lama operasional tersebut sangat rendah bila dibandingkan dengan penelitian Islam et al., (2008) yang menunjukkan bahwa coldstorage di Bangladesh mempunyai lama operasional hingga 9 bulan. Hal ini karena coldstorage objek penelitan hanya digunakan untuk cabai rawit sedangkan di Bangladesh dapat digunakan untuk jenis komoditas lainnya. Biaya total dapat dilihat pada tabel berikut, dimana tabel tersebut menunjukkan bahwa biaya tetap lebih besar dibandingkan dengan biaya tidak tetap. Sebesar $89,5 \%$ dari biaya total merupakan biaya tetap sedangkan biaya tidak tetap sebesar $10,5 \%$ dari biaya total. Sedangkan menurut Kart MCO, (2014) biaya tetap sebesar 60\% dan biaya tidak tetap sebesar $40 \%$. Perbedaan ini karena nilai bunga yang diasumsikan lebih tinggi dibandingkan dengan kajian Kart MCO, (2014) yang hanya sebesar 4\% per tahun. 
Tabel 5. Data Perhitungan Biaya Total Penyimpanan Dingin

\begin{tabular}{lrr}
\hline \multicolumn{1}{c}{ Keterangan } & Nilai & \% \\
\hline Biaya Tetap & & \\
Penyusutan(Rp/bulan) & 130.705 .497 & 46,14 \\
Biaya Tetap Bunga & & \\
modal(Rp/bulan) & 122.953 .271 & 43,40 \\
Biaya Tidak tetap (Rp/bulan) & 29.600 .000 & 10,46 \\
Biaya Total (Rp/bulan) & $\mathbf{2 8 3 . 2 5 8 . 7 6 8}$ & 100 \\
\hline
\end{tabular}

Sumber : Hasil Penelitian

Besarnya biaya tetap dan biaya tidak tetap dalam pembangunan dan operasional coldstorage cabai rawit menyebabkan Koperasi Lais Manekat dibantu oleh pemerintah provinsi, hal ini sejalan dengan penelitian Syafril (2009) yang menyatakan bahwa coldstorage akan memberikan manfaat sosial ekonomi secara berkelanjutan dengan mempertimbangkan keterlibatan pemerintah daerah dan pelaku bisnis untuk melakukan sharing modal. Perhitungan biaya pokok menggunakan persamaan [2]. Asumsi pada perhitungan ini adalah lama operasional 3 bulan per tahun dan bunga modal sebesar 10\% serta kapasitas penuh terpakai.

$$
B p=\frac{R p .283 .258 .768 \text { per bulan }}{400.000 \mathrm{~kg}}=R p .708,146 \text { per bulan } \text { per } \mathrm{kg}
$$

Dari hasil perhitungan di atas dapat disimpulkan bahwa biaya sewa minimal agar koperasi tidak mengalami kerugian dalam operasional coldstorage adalah Rp. 708,146 per bulan per $\mathrm{kg}$. Nilai tersebut lebih tinggi dibandingkan hasil penelitian Kart dan Demircan (2014) yang menunjukkan bahwa biaya pokok sebesar $\$ 0,023$ per kg atau setara dengan Rp. 322 per kg (kurs \$ 1 setara dengan Rp. 14.000). Tingginya biaya pokok karena kapasitas 400 ton sedangkan penelitian Kart dan Demircan (2014) kapasitasnya mencapai 5.000 ton. Gambar berikut ini menampilkan perubahan biaya pokok terhadap perubahan asumsi.



Gambar 7. Perubahan Biaya Pokok Terhadap Perubahan Asumsi

Bunga Modal (a), Kapasitas Terpakai (b) dan Lama Operasional (c)

Berdasarkan kurva pada gambar 7a di atas, pada asumsi lama operasional tetap selama 3 bulan dan kapasitas terpakai 400 ton, biaya pokok semakin meningkat seiring dengan peningkatan bunga modal. Terlihat bahwa perubahan bunga modal dari $10 \%$ menjadi $40 \%$ akan meningkatkan biaya pokok dari Rp. 708,146 menjadi 1087 rupiah per kg per bulan.

Gambar 7b menunjukkan bahwa pada bunga modal tetap 10\% dan lama operasional 3 bulan pertahun, terjadi penurunan biaya pokok seiring dengan peningkatan kapasitas terpakai. Perubahan kapasitas akan mempengaruhi biaya tidak tetap saja karena coldstorage sudah dimiliki oleh Koperasi Lais Manekat. Dari kurva di atas, peningkatan 
kapasitas terpakai penyimpanan dari 200 ton menjadi 400 ton akan menurunkan biaya pokok dari Rp. 1.372 menjadi Rp. 708,146 per kg per bulan.

Biaya pokok akan berubah bergantung pada jam kerja operasional pemakaian coldstorage. Dari gambar $7 \mathrm{c}$, semakin sering coldstorage dipakai maka semakin rendah biaya pokok produksinya. Peningkatan bulan operasional coldstorage dari 3 bulan per tahun menjadi 12 bulan pertahun akan menurunkan biaya pokok dari Rp. 708,146 menjadi Rp. 155 per bulan per tahun. Upaya-upaya peningkatan kapasitas terpakai dan jam kerja operasional coldstorage yaitu penerapan sistem rotasi tanam maupun panen cabai rawit dan kerjasama dengan pelaku komoditi selain cabai rawit yang membutuhkan penyimpanan dingin.

\section{Nilai Tambah Penyimpanan Dingin}

Nilai tambah merupakan salah satu komponen dalam membentuk nilai jual produk, sedangkan nilai produk merupakan nilai yang dimiliki sebuah produk dan terdiri dari nilai tambah pengolahan, nilai bahan baku, dan nilai input lainnya (Dilana 2013). Peningkatan nilai sebagai akibat pengurangan susut selama penyimpanan dengan menggunakan teknologi penyimpanan dingin. Tabel berikut menunjukkan perbandingan nilai tambah penyimpanan dingin dengan penyimpanan konvensional yang dilakukan selama ini.

Biaya pokok digunakan untuk menghitung nilai tambah penyimpanan dingin. Biaya pokok tersebut dalam metode hayami sebagai sumbangan input lain. Berdasarkan analisis biaya pokok, penyimpanan dingin selama 3 bulan membutuhkan biaya sebesar Rp. 708,146 per $\mathrm{kg}$. Nilai tersebut lebih rendah dibandingkan dengan penyimpanan konvensional sebesar Rp. 1.372 per kg. Berdasarkan wawancara mengenai prediksi harga 3 bulan kedepan dan nilai susut terdapat perbedaan signifikan antara penyimpanan konvensional dengan penyimpanan dingin. Keuntungan penyimpanan dingin lebih besar dari pada penyimpanan konvensional, yaitu memperoleh keuntungan Rp. 13.417 per kg selama penyimpanan 3 bulan sedangkan penyimpanan konvensional Rp. 3000 per kg. Peningkatan tersebut diperoleh dengan asumsi harga sebelum disimpan Rp. 22.250 per $\mathrm{kg}$, dan harga jual setelah disimpan Rp. 35.000 per kg. 
Tabel 6. Perbandingan Nilai Tambah Penyimpanan Dingin

\begin{tabular}{clcc}
\hline No & \multicolumn{1}{c}{ Uraian } & $\begin{array}{c}\text { Penyimpanan } \\
\text { Konvensional }\end{array}$ & $\begin{array}{c}\text { Teknologi } \\
\text { Penyimpanan } \\
\text { Dingin }\end{array}$ \\
\hline Output, Input dan Bahan Baku & & \\
1 & Output (Kg/Periode) & 50000 & 50000 \\
2 & Bahan Baku (Kg/Periode) & 50000 & 50000 \\
3 & Tenaga Kerja (HOK/periode) & 13542 & 13542 \\
4 & Faktor Konversi (Kg Output/Kg Bahan Baku) & 1,00 & 1,00 \\
5 & Koefisien Tenaga Kerja (HOK/Kg Bahan Baku) & 0,271 & 0,271 \\
6 & Harga Output (Rp/Kg) & 15000 & 22250 \\
7 & Upah Rata-rata Tenaga Kerja ( Rp/HOK) & 30000 & 30000 \\
Pendapatan dan Keuntungan & & \\
8 & Harga Bahan Baku (Rp/Kg) & 12750 & 12750 \\
9 & Sumbangan Input Lain ((Rp/Kg) & 1372 & 708,146 \\
10 & Nilai Output (Rp/Kg) & 22250 & 35000 \\
$11 \mathrm{a}$ & Nilai Tambah (Rp/Kg) & 8128 & 21542 \\
B & Rasio Nilai Tambah (\%) & 0,365 & 0,615 \\
$12 \mathrm{a}$ & Imbalan Tenaga Kerja (Rp/Kg) & 8125 & 8125 \\
B & Bagian Tenaga Kerja (\%) & 1000 & 0,377 \\
13a & Keuntungan (Rp/Kg) & 3000 & 13417 \\
B & Tingkat Keuntungan (\%) & 0,001 & 0,383 \\
Balas Jasa dari Masing-masing Faktor Produksi & & \\
14a & Marjin (Rp/Kg) & 9500 & 22250 \\
B & Imbalan Tenaga Kerja (\%) & 0,855 & 0,365 \\
C & Sumbangan Input Lain (\%) & 0,032 \\
D & Keuntungan (\%) & 0,144 & 0,063 \\
15 & RC rasio & 1,00 & 1,62 \\
\hline
\end{tabular}

Sumber : Hasil Penelitian

Sidhu et al (2010) menambahkan bahwa untuk meningkatkan nilai tambah dengan penurunan susut perlu kerjasama pemasaran dengan supermarket karena dilengkapi oleh fasilistas precooling, transportasi berpendingin serta adanya ruangan berpendingin di outlet-outletnya. Namun demikian, aktivitas integrasi pasar dan kerjasama supermarket tidak bisa dilakukan oleh individu petani cabai rawit karena skalanya kecil. Koperasi menjadi solusi karena mampu menghimpun cabai rawit dan memasarkan agar terjamin kualitas, kuantitas dan kontinuitas pengiriman produk ke berbagai supermarket.

Tingginya nilai tambah penyimpanan dingin merupakan peluang bagi stakeholders untuk mencegah kerugian dari penurunan harga dan susut penyimpanan konvensional. Analisis rantai nilai menunjukkan ada tiga stakeholder yang dapat menggunakan teknologi penyimpanan dingin yaitu petani, pedagang pengumpul dan pedagang pengecer di beberapa pasar rakyat di Kota Kupang. Dengan keuntungan dan nilai RC yang paling rendah pada petani, teknologi penyimpanan dingin lebih sesuai untuk petani dibandingkan dengan pelaku lainnya. Namun demikian biaya total penyimpanan dingin yang tinggi (Tabel 5) dan disertai dengan jumlah panen petani yang sangat rendah, teknologi penyimpanan dingin perlu dikelola oleh koperasi petani. Hasil penelitian Ito et al (2012) menunjukkan bahwa sistem koperasi merupakan sarana penting bagi petani kecil untuk meningkatkan pendapatan.

Seringkali permasalahan penyimpanan yang terjadi yaitu ketidakmauan petani menyimpan karena membutuhkan uang tunai untuk sehari-hari dan persiapan musim tanam berikutnya. Beberapa strategi agar petani mau melakukan penyimpanan dingin dengan sosialisasi manfaat penyimpanan dingin terutama nilai tambahnya, memperkuat lembaga koperasi dan 
mengaplikasikan sistem resi gudang di penyimpanan dingin. Sistem tersebut sangat prospektif terutama pada saat harga sedang anjlok (Bappebti, 2010). Dengan teknologi penyimpanan dingin dan interaksi antar stakeholders, peluang penawaran cabai rawit akan tetap terkendali.

\section{Kesimpulan}

Berdasarkan analisis biaya pokok, penyimpanan dingin selama 3 bulan membutuhkan biaya sebesar Rp. 708,146 per kg. Nilai tersebut lebih rendah dibandingkan dengan penyimpanan konvensional sebesar Rp. 1.372 per kg. Berdasarkan wawancara mengenai prediksi harga 3 bulan kedepan dan nilai susut terdapat perbedaan signifikan antara penyimpanan konvensional dengan penyimpanan dingin. Keuntungan penyimpanan dingin lebih besar dari penyimpanan konvensional, yaitu memperoleh keuntungan Rp. 13.417 per kg selama penyimpanan 3 bulan sedangkan penyimpanan konvensional Rp. 3000 per kg. Peningkatan tersebut diperoleh dengan asumsi harga sebelum disimpan Rp. 22.250 per kg, dan harga jual setelah disimpan Rp. 35.000 per kg.

Tingginya nilai tambah penyimpanan dingin merupakan peluang bagi stakeholders untuk mencegah kerugian dari penurunan harga dan susut penyimpanan konvensional. Analisis rantai nilai menunjukkan ada tiga stakeholder yang dapat menggunakan teknologi penyimpanan dingin yaitu petani, pedagang pengumpul dan pedagang pengecer di beberapa pasar rakyat di Kota Kupang. Dengan keuntungan dan nilai RC yang paling rendah pada petani, teknologi penyimpanan dingin lebih sesuai untuk petani dibandingkan dengan pelaku lainnya. Namun demikian biaya total penyimpanan dingin yang tinggi dan disertai dengan jumlah panen petani yang sangat rendah, teknologi penyimpanan dingin perlu dikelola oleh koperasi petani.

Seringkali permasalahan penyimpanan yang terjadi yaitu ketidakmauan petani menyimpan karena membutuhkan uang tunai untuk sehari-hari dan persiapan musim tanam berikutnya. Beberapa strategi agar petani mau melakukan penyimpanan dingin dengan sosialisasi manfaat penyimpanan dingin terutama nilai tambahnya, memperkuat lembaga koperasi dan mengaplikasikan sistem resi gudang di penyimpanan dingin. Dengan teknologi penyimpanan dingin dan interaksi antar stakeholders, peluang penawaran cabai rawit akan tetap terkendali.

\section{Ucapan Terimakasih}

Peneliti menyampaikan terima kasih kepada Kementerian Riset, Teknologi dan Pendidikan Tinggi, Direktorat Jenderal Penguatan Riset dan Pengembangan, dan Direktorat Penelitian dan Pengabdian Masyarakat. Ucapan terima kasih juga Peneliti sampaikan kepada Pemerintah Kabupaten Kupang dan semua pihak yang telah membantu dengan caranya masing-masing, untuk kelancaran penyelesaian kegiatan penelitian ini. 


\section{Daftar Pustaka}

ACIAR. 2012. Membuat Rantai Nilai Lebih Berpihak pada Kaum Miskin. Australian Center for International Agriculture Research. Buku Pegangan untuk Praktisi Rantai Nilai. Tabros Indonesia

Agricultural Development International. 2008. Making Value Chains Work Better for the Poor: A Toolbook for Practitioners of Value Chain Analysis. UK Departement for International Development (DFID) Project. Phnom Penh (Combodia): Agricultural Development International

Aung MM, Chang YS. 2014. Temperature Management for the Quality Assurance of a

Perishabel Food Supply Chain. Food Control 40 198-207

Bahtiar J, Kindangen G. 2011. Penerapan Rantai Nilai (Value Chain Analysis) dalam

Rangka Akselerasi Pembangunan Sektor Pertanian di Sulawesi Utara. Balai Pengkajian Teknologi Pertanian (BPTP). Sulawesi Utara

Bappebti. 2010. Pedoman Kelompok Tani Sistem Resi Gudang. Kementerian Perdagangan Republik Indonesia.

Boade VA. 2003. A Conversation About Value Adde Agriculture. Departement of Agriculture Economics, Kansas State University.

Dilana, IA. 2013. Pemasaran dan Nilai Tambah Biji Kakao di Kabupaten Madiun Jawa Timur. Thesis. Bogor: Sekolah Pascasarjana Institut Pertanian.

Direktorat Jenderal Pengolahan dan Pemasaran Hasil Pertanian. 2006. Road map Pascapanen dan Pemasaran Hasil Pertanian. Kementerian Pertanian RI

FAO.2012. Study on Market Appraisal and Value Chain Development of Chili Products in

West Java Food Agriculture Organization, 2012

Hayami Y, Toshihiko, Kawagoe, Yoshinori Marooka, Masdjidin Siregar. 1987. Agricultural Marketing and Processing in Upland Java. A Perspective From A Sunda Village. CGPRT Center. Bogor. $75 \mathrm{p}$

Islam MM, Kabir MH, Sattar MA, Kabir MS. 2008.Management Practices in some Selected Coldstorage in Bangladesh J.Innov.dev.strategy. 2(3):48-54

Ito J, Bao Z, Su Q. 2012. Distributional Effect of Agricultural Cooperative in China : Exclusion of Small Holders and Potential gain on Participation J.Food Policy 37 (2012) 700-709

Kart MCO, Demircan V.2014. An Economic Comparison of Conventional and Modern Coldstorage Facilities Turkey. V 10 n 1 ISSN 1808-2882

Khunt KA, GajiparaHM, Venkariya SB. 2006. Price behaviour of major vegetables in Gujarat State. Indian Journal of Agricultural Marketing, 20: 28-37

Kumar BG, Pramanik SC, Nawaz S. 2004. Economics of production and marketing of vegetables in Andaman and Nicobar Islands. Indian Journal of Agricultural Marketing, 18: 16-22.

Mayrowani H, Agustin NK, Swastika DK, Aziz M. 2013. Analisis Struktur Perilaku Kinerja Pemasaran Sayuran Bernilai Ekonomi Tinggi. Laporan Akhir. Pusat Penelitain dan Pengembangan Sosial Ekonomi Pertanian 
Mutia AK, Purwanto YA, Pujiantoro L. 2014. Perubahan Kualitas Bawang Merah (Allium ascalonicum L) Selama Penyimpanan Pada Tingkat Kadar Air dan Suhu Berbeda. Jurnal Pascapanen. Belum terbit

Navadkar DS, Sale DL, Patil UD. 2005. Marketing of vegetables grown around Pune city. Agricultural Situation in India, 63: 259-65

Rustini S, Prayudi B. 2011. Teknologi Produksi Benih Bawang Merah Varietas Bima Brebes. Risalah Hasil Pengkajian Inovasi Hortikultura di Jawa Tengah. Jawa Tengah (ID). Balai Pengkajian Teknologi Pertanian Jawa Tengah.

Sidhu RS., Sanjay K, Kamal V, dan Parminder S. 2010. Supply Chain Analysis of Onion and Cauliflower in Punjab. Agricultural Economics Research Review. Vol. 23 (Conference Number) 2010 pp 445-453

Syafril M. 2009. Kelayakan Finansial Pembangunan Coldstorage di Provinsi Nusa TenggaraTimur. EPP. Vol. 6 No. $12009: 1-8$

Triyono, Rosyadi I, Ahyani F. 2010. Efisiensi Pengelolaan Pasar Bawang Merah Kabupaten Cirebon. Dinamika Sosial Ekonomi vol 6 no 1. 